University of Wollongong

Research Online

Faculty of Engineering and Information

Faculty of Engineering and Information

Sciences - Papers: Part A

Sciences

$1-1-2006$

\title{
Control stabilisation of an Islanded system with DFIG wind turbine
}

\author{
M Aktarujjaman \\ University of Tasmania \\ Kashem M. Muttaqi \\ University of Tasmania, kashem@uow.edu.au \\ Michael Negnevitsky \\ University of Tasmania, michael.negnevitsky@utas.edu.au \\ Gerard Ledwich \\ Queensland University of Technology, g.ledwich@qut.edu.au
}

Follow this and additional works at: https://ro.uow.edu.au/eispapers

Part of the Engineering Commons, and the Science and Technology Studies Commons

Research Online is the open access institutional repository for the University of Wollongong. For further information contact the UOW Library: research-pubs@uow.edu.au 


\title{
Control stabilisation of an Islanded system with DFIG wind turbine
}

\begin{abstract}
Distributed Generation (DG) is often used to export power to the utility system. Loss of main supply can cause a severe loading mismatch between DG generation and load consumption. Consequently, the voltage and frequency of the islanded system will cross the allowable limit. Due to this fact, it is essential to control the voltage and frequency in the islanding mode of operation. In this paper, control stabilisation of an islanded system with a doubly-fed induction generator (DFIG) wind turbine has been addressed. Wind DG produces variable output and is not capable to produce enough reactive power. Hence, it is imperative to develop better control system for the islanding operation of wind system. Voltage and frequency control strategies of a doubly fed induction generator (DFIG) with energy storage for islanding operation have been developed. The investigation has been carried out through modeling of a doubly fed wind turbine and an energy storage system using SimPowerSystems tools of MATLAB. The simulations have been carried out in stand-alone operation of DFIG during various wind penetration.
\end{abstract}

\section{Keywords}

turbine, wind, system, islanded, dfig, control, stabilisation

Disciplines

Engineering | Science and Technology Studies

\section{Publication Details}

M. Aktarujjaman, K. A. Kashem, M. Negnevitsky \& G. Ledwich, "Control Stabilisation of an Islanded

System with DFIG Wind Turbine," in First International Power and Energy Conference (PECon 2006), 2006, pp. 312-317. 


\title{
Control Stabilisation of an Islanded System with DFIG Wind Turbine
}

\author{
M. Aktarujjaman, Student Member, IEEE, M.A. Kashem, Senior Member, IEEE, M. Negnevitsky, Member, \\ IEEE, and G. Ledwich, Senior Member, IEEE
}

\begin{abstract}
Distributed Generation (DG) is often used to export power to the utility system. Loss of main supply can cause a severe loading mismatch between DG generation and load consumption. Consequently, the voltage and frequency of the islanded system will cross the allowable limit. Due to this fact, it is essential to control the voltage and frequency in the islanding mode of operation. In this paper, control stabilisation of an islanded system with a doubly-fed induction generator (DFIG) wind turbine has been addressed. Wind DG produces variable output and is not capable to produce enough reactive power. Hence, it is imperative to develop better control system for the islanding operation of wind system. Voltage and frequency control strategies of a doubly fed induction generator (DFIG) with energy storage for islanding operation have been developed. The investigation has been carried out through modeling of a doubly fed wind turbine and an energy storage system using SimPowerSystems tools of MATLAB. The simulations have been carried out in stand-alone operation of DFIG during various wind penetration.
\end{abstract}

Index terms - Islanding operation, DFIG, Energy storage, Distributed generation and voltage stability improvement. ${ }^{1}$

\section{INTRODUCTION}

Recently, renewable resources such as wind, solar, biomass etc are connected into the distribution network to contribute in loss reduction, improve voltage quality, and increase the capacity of the network. Inclusion of distributed generation into distribution network is employed to export power into the utility system. The controllability of DG is often limited due to unpredictable nature of renewable resources. The benefits of DG can be utilised with minimum control because utility will play major role for controlling voltage and frequency during grid connected mode of operation. Utility grids are frequently interrupted by transmission system events such as lightning strikes, equipment failures, and downed power lines. These system events cause an intentional or unintentional islanding mode of operation. Loss of main supply can cause severe overloading problems into the islanded system. Consequently, voltage and frequency will cross its allowable margin. The operation capability of distributed generation during loss of main supply can ensure continuity of power supply and reduce the level of load shedding.

The probability of supply interruption in rural or weak grid is higher then strong grid or urban area. DC link storage system of DFIG with proper converter control strategy can

This research has been financially supported by the Australian Research Council under ARC Linkage Grant K0014223 "Integration of Distributed and Renewable Power Generation into Electricity Gird Systems", collaboration with Aurora Energy, Tasmania.

Md. Aktarujjaman, Dr. Mohammad A. Kashem, and Assoc. Prof. Michael Negnevitsky are with the School of Engineering, University of Tasmania, Hobart, Australia; and Prof. Gerard Ledwich is with the School of Engineering Systems, Queensland University of Technology, Brisbane, Australia, (emails: mda0@utas.edu.au; M.Kashem $@$ utas.edu.au; Michael.Negnevitsky@utas.edu.au; g.ledwich(a) qut.edu.au). provide uninterruptible power supply to the customers. In islanding operation, the load side converter can regulate frequency and ensure continuity of power supply to all essential services. Further more, it will absorb initial impact of central generation and ensure slow load increases for distant generator during black start.

Doubly fed induction generator is able to operate in the variable speed operation. Real and reactive power can be also controlled independently. Reduced converter rating is another key feature of DFIG equipped wind turbine. In the case of variable speed operation, the DFIG rotor is connected with stator via two AC-DC and DC-AC converters and the stator is directly connected with the grid [1-2, 6-7].

DG can operate with the grid system to support the grid voltage or as an isolated system to support customers isolated from the grid. Islanding occurs when a portion of the distribution system becomes electrically isolated from the utility but with DG that sometimes to supply into the isolated system [3]. An islanding situation may occur as a deliberate state of operation or as an unintended outcome. The island can be characterised as being either generation poor or generation rich. An over generated islanded system can be stabilised by governor system; the stabilisation under under-generation requires special planning and usually dependent on a load shedding scheme. The control strategy of DG should be designed so that DG can support to stabilised an islanded system and help to prevent the total black out of the system [4].

After disconnection from main grid, the islanded system initially faces generation mismatch and leads to offer an over generated or under generated situation. Generation under supply leads to under frequency and under voltage problems in the islanded system; whereas generation rich or generation over supply can lead to over frequency and over voltage issues [5]. As a result, system voltage and frequency will fall below the standard limit. Hence, an imperative control system is required to stabilize the islanded system.

In the case of islanding operation, where the main grid is disconnected from the wind turbine and its load, wind turbine cannot start alone due to the inability of reactive power generation. The converter is supported by energy storage based inverter and can generate required reactive power for the wind turbine to start. DFIG with energy storage can supply power to the crucial loads. Excess power from the wind turbine can be absorbed by the storage system up to the threshold limit. If extracted power exceeds the limit, then pitch control will apply for maintaining the system frequency within the expectable range. So energy storage based system gives the capability of islanding operation. 
In this paper, the control issues of an islanded system has been discussed and identified. A new control method has been developed and modeled. The behavior of the controller has been modelled and simulation results have been presented

\section{CONTROL METHODOLOGY FOR ISLANDING OPERATION}

Islanded system often faces problems in two different areas which are rich or over generation and poor or under generation. The DFIG with storage system can be assumed as two source of power in the islanding mode of operation: one is DFIG with rotor side converter and another is storage with load side converter. The control of the rotor side converter will allow capturing maximum wind power by controlling torque of the machine according to the power tracking characteristics of the wind turbine. The combination of induction generator and rotor side converter is able to control real and reactive power independently. On the other side, the load side converter with storage behaves like inverter based DG. In the case of islanding operation, storage system will provide system stability. It will regulate the system frequency and voltage. According to the frequency and voltage deviation due to the load demand and wind variation, storage controller will continuously adjust output active and reactive powers in order to keep the energy balance and also frequency and voltage close to their nominal values. In over generated situation, controller will sink energy to the storage system up to maximum charging limit. In an under generation situation, when load demand is higher than wind production, controller will apply load shedding policy.

In this paper, for simulation purpose, a dummy load is applied to the islanded system for stabilising system frequency to the reference of $50 \mathrm{~Hz}$.

\section{A. Control of Load bus voltage}

In an islanded system, load bus voltage or system voltage is controlled by the load side converter. For better power factor, load side converter is used to inject reactive power to the system. To achieve 1 p.u voltage in the output, load side converter uses bus voltage control loop. In this control loop, measured terminal voltage is compared with the reference voltage of 1 p.u. and the difference is compensated by the PI controller.

\section{$B$ Control of System frequency}

In an islanded system, system frequency depends on close balance of generated and consumed power. Storage system is used to sink and source of excessive or shortage of wind power. To keep the islanded system's frequency as well as voltage at their predetermined value (e.g. frequency of 50 $\mathrm{Hz}$, voltage of 1 p.u.), storage system should always provide the required power to the system. The approach used for frequency and voltage control is conventional $f-P$ and $v-Q$ droop characteristics into the storage system controller as shown in Fig.1 (a) and 1(b).

Due to high wind and load demand variability, a dummy load is implemented in addition with storage system to keep the system frequency within the limit. The control of dummy load is followed a look-up table. According to the frequency deviation, the dummy load controller produces control signal for the variable look-up table to connect or disconnect appropriate load with the system.

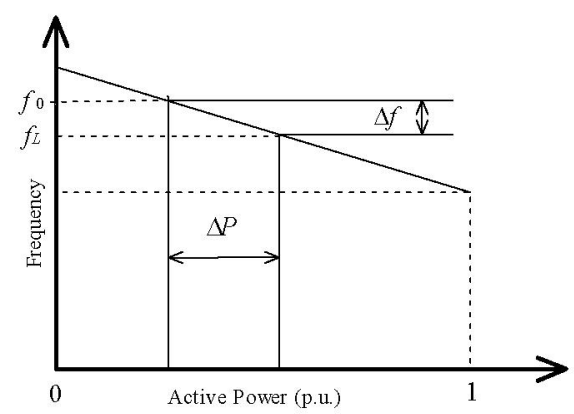

Fig.1(a). Typical frequency droop characteristics

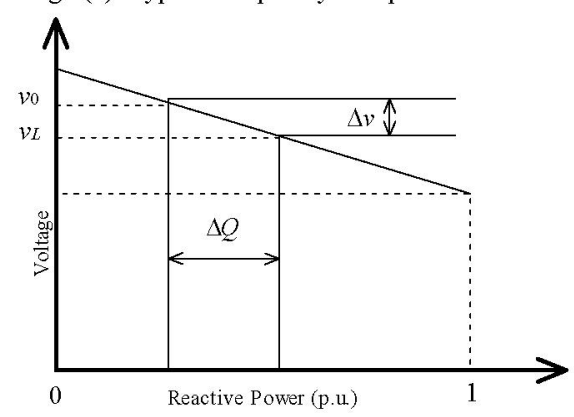

Fig. 1(b). Typical voltage droop characteristics

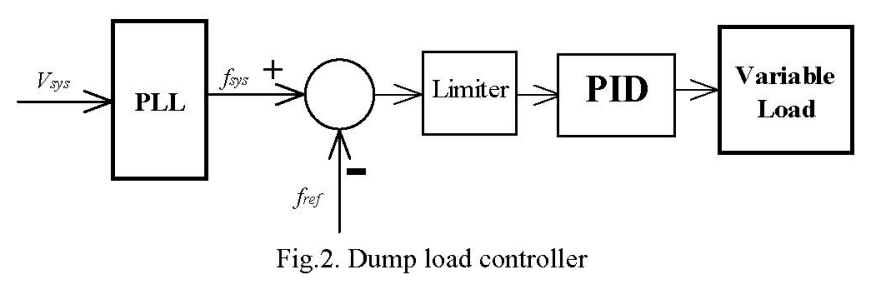

C. Control of DC link Voltage

The control of DC link is necessary to obtain load tracking capability of the DFIG system. This controller is used to sink or source energy to and from storage system. Power required by the rotor side converter can be compensated by the storage system.

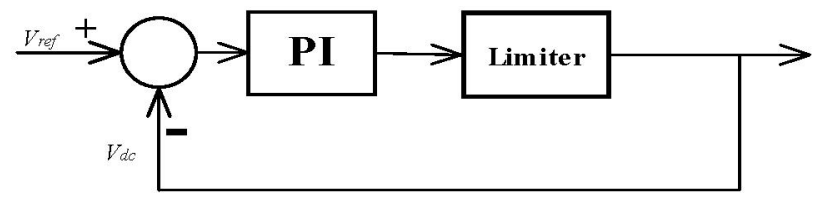

Fig.3. DC link Voltage controller

The active component is used to control the DC link voltage in order to balance the required power and output power within the maximum capacity of the storage system.

D. Control of Load Side Converter

The load side converter is used vector control technique for controlling voltage and frequency of the system. PI controller is used for compensating the error. The compensated signal is determined based on the following equation:

$$
C_{\text {sig }}=k_{p} . \Delta e+\int k_{i} . \Delta e
$$


where $k_{p}$ and $k_{i}$ are the proportional and integral constant of the controller, respectively; and $\Delta e$ is the difference between reference and measured signal.

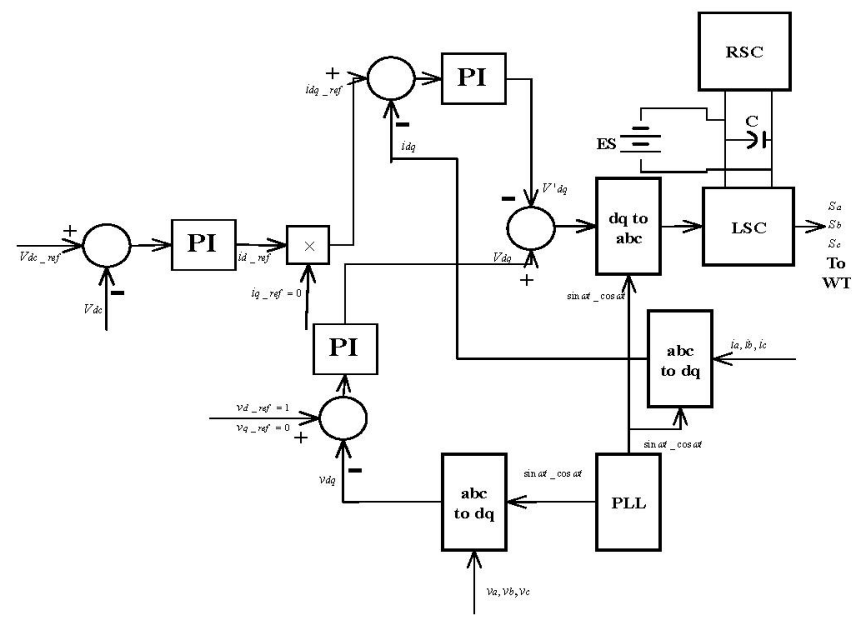

Fig.4. Load Side Converter (LSC) controller

Fig. 4 shows the proposed control structure for the load side converter. In the voltage control loop, terminal voltage measured and compared with the reference voltage, which is 1 p.u. the output of voltage control loop is compared with the output of the inner current loop of the DC link voltage controller. A PLL is used for frequency reference. The PI controller is responsible for regulating the difference.

\section{System Description}

The system in the paper consists of a doubly fed induction generator (DFIG), an energy storage system is connected in DC link, local loads and a tie breaker shown in Fig. 5 and is connected with a weak grid. Load 3 is assumed to be disconnected from the grid system with DFIG followed by breaker operation. The generator used in DFIG is a woundrotor induction machine where the rotor terminals are fed via a back-to-back PWM voltage source converter. In a typical arrangement, the rotor side converter is responsible for controlling the speed of the generator and stator reactive power, while the load side converter will responsible for regulating DC link voltage [1-2,6-7]. Through inclusion of energy storage into the DC link, The load side converter not only provides the real power sink and source capability for reducing power fluctuation but also provides extra reactive power for the system to enhance voltage stability significantly.

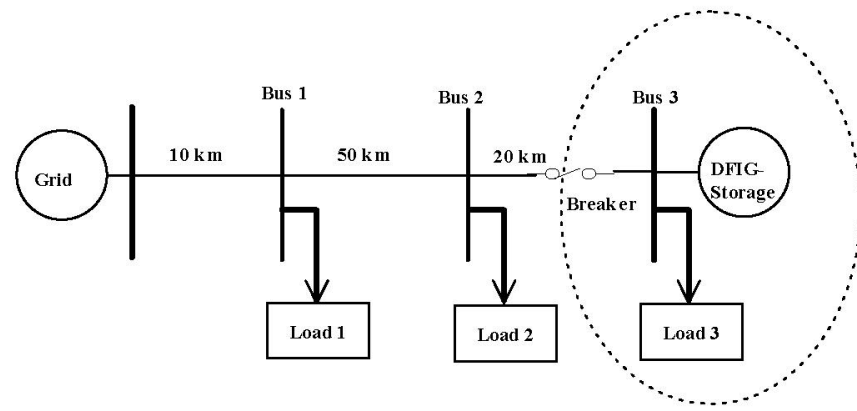

Fig.5: Single line diagram of DFIG wind turbine equipped system

Fig.6 shows a typical arrangement of a doubly fed induction generator (DFIG) equipped wind turbine with back to back PWM converter and a battery storage system connected to the DC link of [6]. The storage system controller maintains smooth operation of the system for grid connected mode as well as islanding mode. The storage controller receives control signal from the available wind energy and grid system. The state of charge of the storage system also plays major role for the storage participation in the different situations.

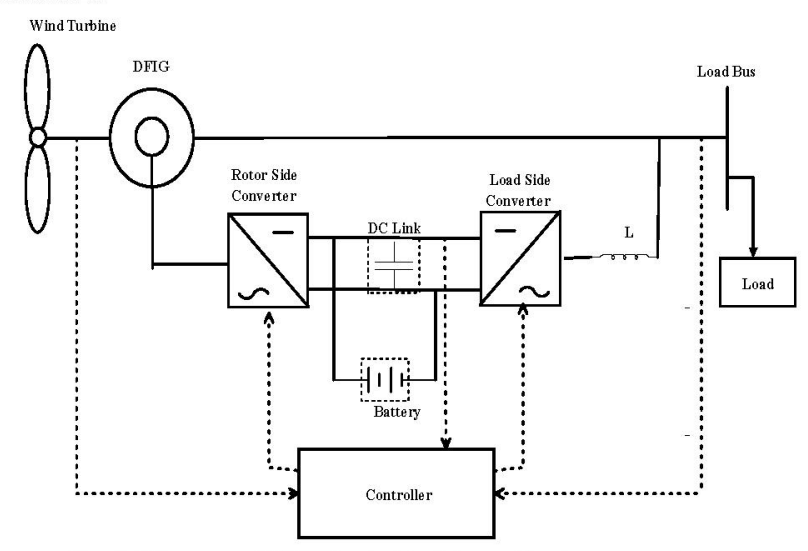

Fig.6: Diagram of DFIG wind turbine with storage system

The storage system will provide instantaneous active power compensation to the customer from few seconds to few hours depending on the size of storage system [8]. It can also contribute to frequency control during islanding mode of operation by providing required active and reactive power to the system. It provides power to the load following the characteristics of the DFIG by the amount of power required to balance the islanded system with significant load changes.

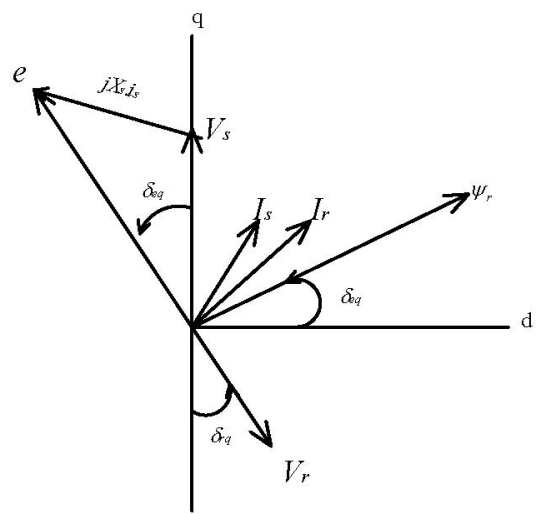

Fig.7: Vector representation of the operating conditions of a DFIG

Fig. 7 shows the vector representation of the operating condition for a DFIG [7]. Here $e$ represents internal voltage vector in the stator often refered to as the voltage behind trnsient reactance. The magnitude of the internal voltage $e$ depends on the magnitude of the rotor flux voltage vector $\psi_{r}$. The flux as well as internal voltage both depend on the magnitude of $V_{r}$ and the slip. Slip manitude and sign are changed by the turbine speed. According to the sign of the slip, internal voltge $e$ lies in or out of phase with $V_{r}$. Sign is determined by the super and sub synchronous operation of the DFIG. The angle $\delta_{e q}$ is the angle between internal voltage $e$ and stator voltage $V_{s}$. This angle is determined by the output power of the DFIG.

\section{A. Wind model}

Wind turbine is a non-linear system whose output depends on optimal values of various parameters. Total power of a wind turbine can be defined as [9], 


$$
P_{\text {wind }}=0.5 \rho A_{r} v^{3}
$$

where $\rho$ is the air density, $A_{r}$ is the area swept by the rotor and $v$ is the wind speed. The wind power output is given by the power curve, depending on the wind speed, which is expressed as [10],

$$
P_{\text {wind }}=\left\{\begin{array}{cl}
P_{\text {rated }} & \text { for } v_{r}<v \leq v_{o} \\
P(v) & \text { for } v_{i}<v \leq v_{r} \\
0 & \text { for } v_{i}>v>v_{o}
\end{array}\right.
$$

where $v_{i}, v_{r}$ and $v_{o}$ are the cut-in, rated and cut-off wind speed, respectively. The function, $P(v)$, describes the wind power between cut-in wind speed and rated wind speed.

Average wind power depends on the value of turbine performance coefficient.

$$
P_{\text {avg }}=P_{\text {wind }} C_{p}
$$

where, $C_{p}$ is the power coefficient. According to Betz the ideal power coefficient will be $59 \%$ in the lossless power extraction. Actual power coefficent $C_{p}$ is less than $59 \%$. In practice, a wind turbine generator with good blade profile may reach to $0.5[10]$.

\section{Storage system}

Storage system will play a major role for controlling frequency and voltage in islanded mode of operation. The energy storage system can be characterised by its charging efficiency $\eta_{c h}$ and discharging efficiency $\eta_{d c h}$ as follows [10]:

$$
\begin{aligned}
& E_{c h}=\eta_{c h}\left(P_{c h}\right) \cdot P_{c h} \\
& E_{d c h}=\frac{P_{d c h}}{\eta_{d c h}\left(P_{d c h}\right)}
\end{aligned}
$$

where $E_{c h}$ and $E_{d c h}$ are the stored and discharged energy respectively. In the case of charging and discharging system with $100 \%$ efficiency, the stored energy in the charging phase will be equivalent to the charging and the discharged energy and the charging power will be the same as the discharging power. The State of Charge (SOC) of the energy storage needs to create control signal for the operation of islanding mode of operation. A storage system can be composed of a set of batteries in parallel and series connection. The equivalent circuit of battery can be represented as shown in Fig. 8 [11]:

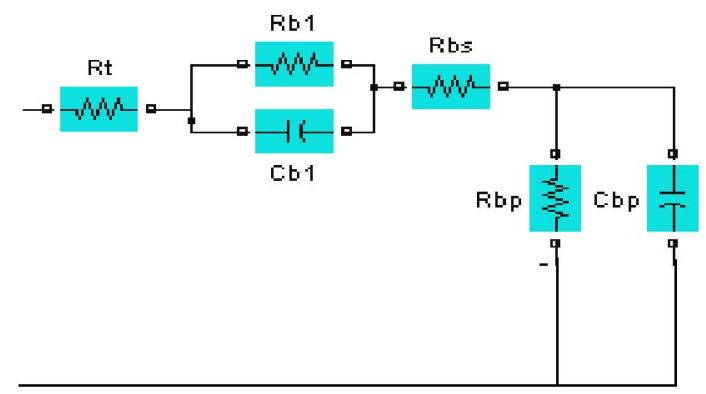

Fig.8: Equivalent battery storage system

$\mathrm{Cbp}=$ battery capacitance;

$\mathrm{Rbp}=$ self discharge resistance;
$\mathrm{Rbs}=$ internal resistance;

$\mathrm{Rbl}=$ overvoltage resistance;

$\mathrm{Cbl}=$ overvoltage capacitance;

$\mathrm{Rt}=$ connecting resistance;

Capacity of storage is represented by the $\mathrm{kWh}$. The size of the capacitor in the model usually represents the size of the storage system. The capacitance of that model can be determined from following equation [11]:

$$
C b p=\frac{k W h \times 7200 \times 10^{3}}{\left(V_{b p_{-} \max }^{2}-V_{b p_{-} \min }^{2}\right)} \quad \text { Farad }
$$

where $V_{b p_{-} \max }$ and $V_{b p_{-} \text {min }}$ are the maximum and minimum voltage across battery capacitance, respectively.

The purpose of the energy storage in the DC link is to store or supply power to the system in order to reduce the power fluctuation in islanding mode of operation. In the situation of excessive wind power, the excess power is used to charge the storage through the line side converter. Stored power can be used when the wind power output is less than the desired level or in the situation of no wind power. The real power $\left(P_{b}\right)$ and reactive power $\left(Q_{b}\right)$ stored or supplied from the storage system are [11]:

$$
\begin{aligned}
& P_{b}=V_{b t} I_{b} \cos \phi \\
& Q_{b}=V_{b t} I_{b} \sin \phi
\end{aligned}
$$

Where $V_{b t}$ and $I_{b}$ are the terminal voltage and current of the storage, respectively. $\phi$ is the angle between terminal voltage and current of of the storage system.

\section{SIMULATION RESULTS AND DISCUSSION}

Simulations have been carried out using MATLAB SimPowerSystems. System parameters are given in Appendix-A. Two cases have been investigated and results are presented. All simulations are run with the $10 \mathrm{sec}$ duration with the different wind situation. For simulating under and over generation situations, the wind speed varies from $5 \mathrm{~m} / \mathrm{s}$ to $14 \mathrm{~m} / \mathrm{s}$. This variation is suitable for observing super and sub-synchronous situation of an islanded system. The responses and behaviors of the controller and system are also simulated in the case of no wind. According to the turbine characteristics, cut in, rated, and cut off speed are $5 \mathrm{~m} / \mathrm{s}, 11 \mathrm{~m} / \mathrm{s}$, and $25 \mathrm{~m} / \mathrm{s}$, respectively. Equivalent battery storage is constructed for this simulation is shown in Fig. 5 . The capacitor is used to determine the storage size. A 1.50 MW wind turbine is connected with a weak grid is considered. In grid connected mode, wind turbine captures maximum power from the wind and delivers to the utility. The voltage and frequency are controlled by the utility. Due to the grid events, circuit breaker operates and makes encircle portion of Fig. 1 disconnected from the grid. After disconnection, the encircle portion (DFIG and load;) is assumed to operate as an islanded system. It is also assumed that the isolated load is $300 \mathrm{~kW}$. For the sake of simplicity, it is assumed that the islanded system start with minimum stored energy in the storage system and load is supplied by wind output power. Fluctuating or excess wind generation is absorbed by dump load and storage system. Simulation results show the effectiveness of the control system of line side converter during under and over generation situation. Investigations are conducted on the effect of the new control 
system in islanding operation. Participation of storage system during the absence of wind is also investigated.

Fig.9 shows responses of a DFIG-storage system during islanding mode of operation in the case of variable wind speed. Fig. 9(a) shows that the load bus voltage within prescribed limit. The variation of bus voltage is approximately between $0.98 \mathrm{p} . \mathrm{u}$ and $1.02 \mathrm{p} . \mathrm{u}$. The variation of system frequency is approximately $49.8 \mathrm{~Hz}$ to $50.2 \mathrm{~Hz}$ as shown in Fig. 9(b). This variation shows that the controller is active to control the system frequency within standard limit.

Figs. 9(c) and 9(d) show the real power (P) flow and reactive power $(\mathrm{Q})$ in the islanded system respectively, where real power $(\mathrm{P})$ is supplied by wind power and the reactive power $(\mathrm{Q})$ is supplied through lone side converter.

Figs. 9(e) and 9(f) show the DC link voltage variation and the generator speed, respectively. The DC link voltage varies between $1180 \mathrm{~V}$ to $1240 \mathrm{~V}$ volt dc approximately as shown in Fig. 9(e). In Fig. 9(f), the generator speed has been increased upto 1.1 p.u. at 4 second of time. After that it starts falling as a response of wind speed.

Figs.9(g) and $9(\mathrm{~h})$ show the dump load in $\mathrm{kW}$ and wind speed in $\mathrm{m} / \mathrm{s}$. Dump load has been used for stabilising islanded system's frequency in over generated mode of islanding operation. Wind speed varies from $14 \mathrm{~m} / \mathrm{s}$ to $5 \mathrm{~m} / \mathrm{s}$, which creates over and under generation situation in the islanded system.

In the case of over generated situation, storage system and dump load are used to stabilise the islanded system's frequency and voltage by controlling the excessive wind generated power. The process of controlling includes charging storage system and dumping excessive load. It is noted that pitch control is not applied here for simplicity. The dump load control can be replaced by a pitch angle control. After 7 seconds from the simulation start, the islanded system is experienced under generation situation, which is controlled by injecting more real power from storage system through load side converter. Both cases, the load is supported by the supply of $300 \mathrm{~kW}$ real power from the DFIG and storage system as shown in Fig. 9(c).
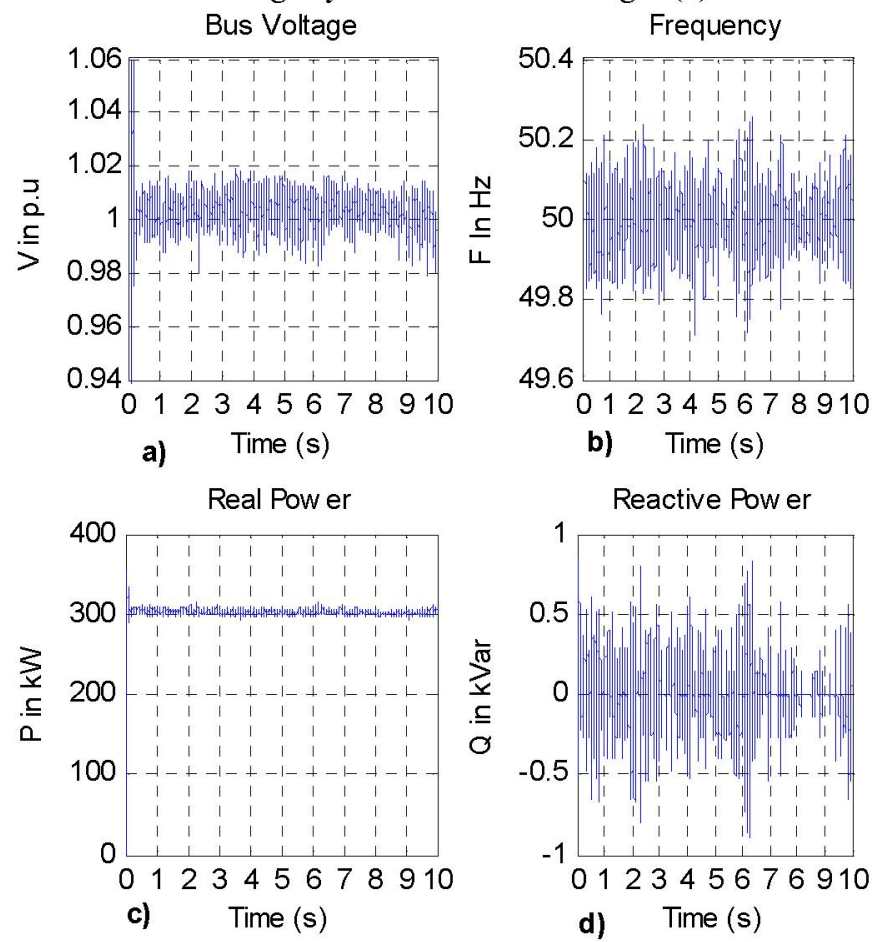
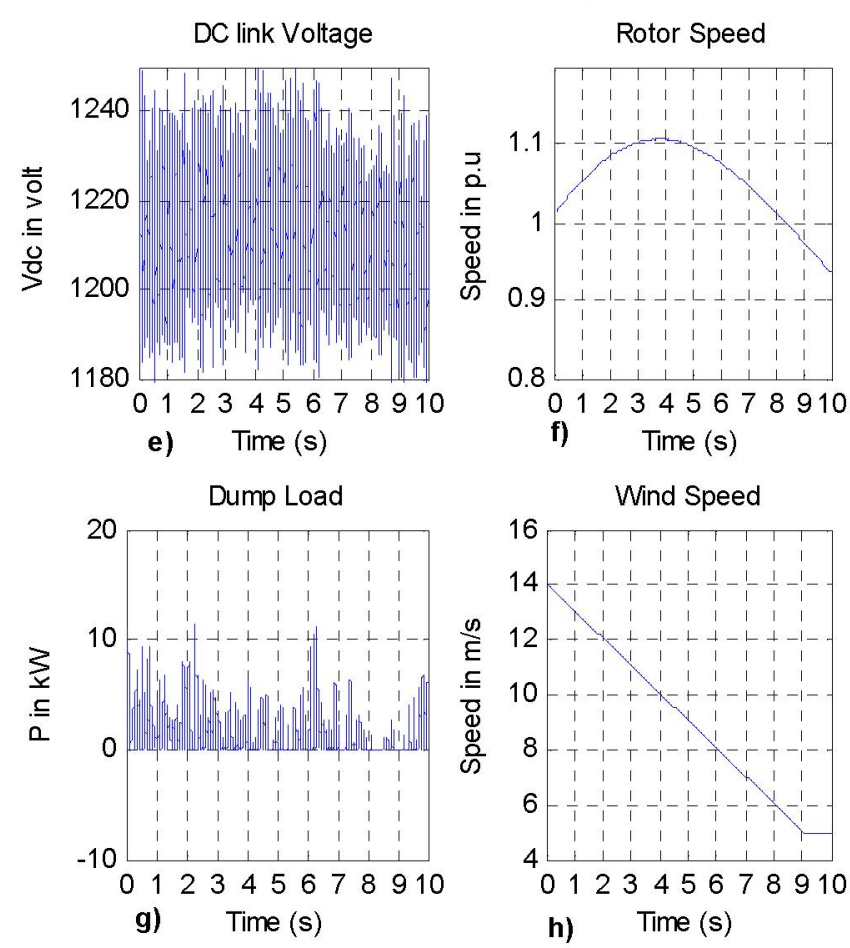

Fig.9 Responses of DFIG and storage system in islanded operation: a) Bus voltage b) System Frequency, c) Real power, d) Reactive power, e) DC link voltage, f) Rotor speed, g)Dump load, h) Wind speed.

Fig.10 shows responses of DFIG and storage system during islanding mode of operation in no wind situation. This could be worst case scenario. The simulation results show that with the help of storage system in the DC link of the DFIG can supply the power a limited time.
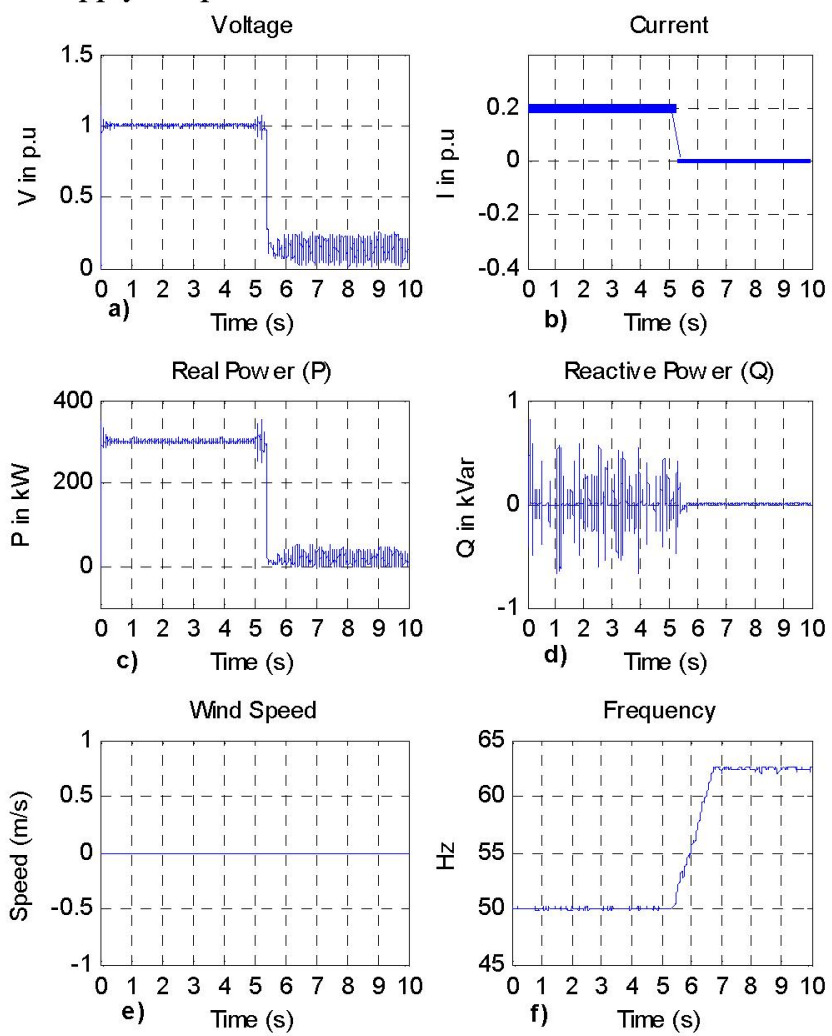

Fig. 10: Responses of DFIG and storage system in islanded operation: a) Bus voltage b) System current, c) Real power, d) Reactive power, e) Wind speed, f) Frequency. 


\section{CONCLUSION}

In this paper, the capability of islanding operation of a DFIG with energy storage system in the DC link has been investigated with the help of SimPowerSystems toolbox of MATLAB. The proposed control system in this proposed arrangement of DFIG is able to stabilise the islanded system's frequency and voltage within the specified limit. Control system also shows the ability to operate the islanded system in over- and under-generated situation. In the case of over generated situation, storage and dump load controller participate for keeping the system frequency within frequency limit. In the case of under- or poor-generated situation, the stored energy can be used to keep the system frequency within the limit. This ability ensures the continuity of the supply in the case of emergency and utilises maximum energy extraction from the wind power.

$$
A P P E N D I X-A
$$

\section{Wind turbine:}

Rating:

$$
1500 \text { Watt }
$$

\section{Generator: Doubly Fed Induction Generator}

$\begin{array}{ll}\text { Stator resistance } & R_{s}=0.00706 \mathrm{p} . \mathrm{u} \\ \text { Stator inductance } & L_{s}=0.171 \mathrm{p} . \mathrm{u} \\ \text { Magnetizing inductance } & L_{m}=2.9 \mathrm{p} . \mathrm{u}\end{array}$

Inertia constant $\mathrm{H}=\mathbf{5 . 0 4}$

Poles $=6$

Battery:

Equivalent Capacitance $C_{b}=18000 \mathrm{~F}$

\section{Inverter: Each}

Rating: $450 \mathrm{~W}$

\section{Line parameters:}

Positive- sequence resistance $R_{1}=0.1153 \Omega / \mathrm{km}$

Zero-sequence resistance $R_{0}=0.413 \Omega / \mathrm{km}$

Positive-sequence inductance $L_{1}=1.05 \mathrm{e}-03 \mathrm{H} / \mathrm{km}$

Zero-sequence inductance $L_{0}=3.32 \mathrm{e}-03 \mathrm{H} / \mathrm{km}$

Positive-sequence capacitance $C_{1}=11.33 \mathrm{e}-09 \mathrm{~F} / \mathrm{km}$

Zero-sequence capacitance $C_{0}=5.01 \mathrm{e}-09 \mathrm{~F} / \mathrm{km}$

\section{REFERENCES}

R. Peña, J. C. Clare, and G. M. Asher, "Doubly fed induction generator using back-to-back PWM converters and its application to variable speed wind-energy generation," Proc. Inst. Elect. Eng., Elect. Power Appl., vol.143, no. 3, pp. 231-241, May 1996.

A. Miller, E. Muljadi, and D. Zinger, "A Variable Speed Wind Turbine Power Control", IEEE Trans. On Energy Conversion, Vol. 12, No. 2, June 1997, pp. 181-186.
M.A. Kashem and G. Ledwich, "Anti-islanding protection and islanding operation of grid connected hydropower distributed generation",Int. Journal of Global Energy Issues, Vol.24,Nos.1/2, 2005, pp.76-85.

F. Katiraei, M.R. Iravani and P.W. Lehn,"Micro-grid autonomous operation during and subsequent to islanding process", IEEE Transactions on Power Delivery, Vol.20, No.1, 2005, pp. 248-257.

R.A. Walling and N.W. Miller, "Distributed generation islandingimplications on power system dynamic performance", Proc. of IEEE PES Summer Meeting, Vol. 1, 2002, pp. 92- 96.

C. Abbey and G. Joss, "Integration of Energy Storage with a Doubly-Fed Induction Machine for Wind Power Generation",IEEE PESC 2004, Aachen, Germany, July 2004.

F. Michael Hughes, Olimpo Anaya-Lara, N. Jenkins, and G. Strbac, "Control of DFIG-Based Wind Generation for Power Network Support", IEEE Transactions on Power Systems, Vol.20, No.4, 2005, pp. $1958-1966$.

W.R.Lachs, and H. Tabatabaci-Yazdi, "Energy Storage in Power Systems", IEEE Int. Conference on Power Electronics and Drive Systems, PEDs'99, July 1999, pp.843-848.

G.M. Masters, "Renewable and Efficient Electric Power Systems", IEEE press, Wiley-Interscience, Hoboken, New Jersey, 2004.

Magnus Korpas, "Distributed Energy Systems with Wind Power and Energy Storage", Doctoral Thesis, Norwegian University of Science and Technology, Trondheim, Norway, 2004.

C. F. Lu, C.C. Liu, and C.J. Wu, "Dynamic modelling of battery storage system and application to power system stability", IEE Proc. Gener. Trans. Distribution, Vol.142, No. 4, July 1995, pp.429-435.

\section{BIOGRAPHIES}

Md. Aktarujjaman (M'00) was born in Bangladesh in 1975. He received the B.Sc.TE. from the Islamic University of Technology, Bangladesh, in 2000. He obtained Masters in Information Technology from Charles Sturt University, Australia in 2002. He is currently pursuing the $\mathrm{PhD}$ degree at the University of Tasmania. His special fields of interests are power system analysis, renewable energy, distributed generation, power system control and protection.

M. A. Kashem (A'O0-SM'05) was born in Bangladesh in 1968. He received the Ph.D. degree from Multimedia University, Malaysia, in 2001. Currently, he is a Lecturer at the School of Engineering, University of Tasmania, Australia. He was associated with the Queensland University of Technology, Australia as a Postdoctoral Research Fellow from 2000 to 2002. Previously, he also worked for Multimedia University as a Lecturer for three years. His special fields of interests include distributed generation, renewable energy, distribution system automation, power system planning, and artificial intelligence. He has published more than 50 technical papers in these areas.

Michael Negnevitsky (M'95) received the B.S.E.E. (Hons.) and Ph.D degrees from Byelorussian University of Technology, Minsk, Belarus, in 1978 and 1983, respectively. Currently, he is an Associate Professor in the School of Engineering at the University of Tasmania, Hobart, Australia. From 1984 to 1991, he was a Senior Research Fellow and Senior Lecturer in the Department of Electrical Engineering, Byelorussian University of Technology. After arriving in Australia, he was with Monash University, Melbourne, Australia. His interests are power system analysis, power quality, and intelligent systems applications in power systems. Dr. Negnevitsky is a Chartered Professional Engineer, a Senior Member of the Institution of Engineers Australia, and a Member of CIGRE AP36 (Electromagnetic Compatibility), Australian Technical Committee.

Gerard Ledwich (M'73-SM'92) received the Ph.D. in electrical engineering from the University of Newcastle, Australia, in 1976. He has been Chair Professor in Electrical Asset Management at Queensland University of Technology, Australia, since 1998. He was Head of electrical engineering at the University of Newcastle from 1997 to 1998. Previously, he was associated with the University of Queensland from 1976 to 1994. His interests are in the areas of power systems, power electronics, and controls. Prof. Ledwich is a Fellow of the Institution of Engineers Australia. 